Aim of the study: To was to determine the impact of chronic obstructive pulmonary disease (COPD) and active smoking on the efficacy of chemotherapy and complete blood count (CBC) in patients with non-small cell lung cancer (NSCLC).

Material and methods: The retrospective evaluation included 50 patients with stage IIIB-IV NSCLC, who started cisplatin-based chemotherapy. Peripheral blood CBC values were collected for testing before chemotherapy and after the first and third cycles.

Results: COPD was diagnosed in $49 \%$ of patients, while $42 \%$ of those enrolled were current smokers. Current smoking $(p=0.92)$ and COPD $(p=0.91)$ status did not affect the response to treatment. The non-COPD population presented a significantly higher pretreatment absolute lymphocyte count (ALC) than the COPD population (2.31 vs. $\left.1.81 \times 10^{9} / l ; p=0.0374\right)$. Also, only the non-COPD group demonstrated an elevated absolute monocyte count (AMC) following the first and third cycles of chemotherapy $(p=0.004)$. In current smokers, pretreatment values for white blood cells (WBC), absolute neutrophil count (ANC), and platelets (PLT) were higher than in the ex-smoker population (WBC 9.94 vs. $8.7\left(\times 10^{9} / 1\right) ; p=0.01$; ANC 6.47 vs. $5.61\left(\times 10^{9} / l\right) ; p=0.037$; PLT 316 vs. 266 ( $\left.\left.\times 10^{9} / l\right) ; p=0.049\right)$. Ex-smokers demonstrated AMC level elevation after the first cycle of chemotherapy and PLT level elevation after the third cycle, while current smokers also demonstrated an early decrease in LMR. Conclusions: COPD and smoking induce chronic systemic inflammation and oxidative stress, which influence the results of standard laboratory tests, but do not change the response rate of lung cancer on chemotherapy.

Key words: non-small cell lung cancer, chronic obstructive pulmonary disease, smoking, chemotherapy.

Contemp Oncol (Pozn) 2016; 20 (5): 407-413 DOI: $10.5114 /$ wo.2016.64605

\section{A retrospective evaluation of associations between chronic obstructive pulmonary disease, smoking, and efficacy of chemotherapy and selected laboratory parameters in patients with advanced non-small cell lung cancer}

Rafał Czyżykowski ${ }^{1}$, Dariusz Nowak ${ }^{2}$, Anna Janiak ${ }^{1}$, Anna Włodarczyk ${ }^{2}$, Agata Sarniak $^{2}$, Magdalena Krakowska ${ }^{1}$, Piotr Potemski ${ }^{1}$

${ }^{1}$ Chemotherapy Department, Mikołaja Kopernika Memorial Hospital in tódź, Medical University of Lodz, Lodz, Poland

${ }^{2}$ Chair of Experimental and Clinical Physiology, Medical University of Lodz, Lodz, Poland

\section{Introduction}

Lung cancer is the most common newly-diagnosed malignancy other than non-melanoma skin cancer, and the leading cause of cancer-related death worldwide. In 2012, 1.8 million people developed lung cancer and approximately 1.6 million died because of it [1]. The following year, lung cancer was detected in about 21,000 patients in Poland, and about 22,000 died. Non-small cell lung cancer (NSCLC) accounts for $85 \%$ of all lung cancers and has a strong aetiological association with smoking. About $10-20 \%$ of chronic smokers develop lung cancer, and about $20 \%$ of smokers suffer from chronic obstructive pulmonary disease (COPD). Cigarette smoking generates chronic inflammation in the airways and systemic oxidative-stress reactions. The pro-inflammatory and immunosuppressive properties of cigarette smoke impair the immune response [2]. Inflammation seems to play a crucial role in the development and progression of many tumours by promotion of proliferation, cell survival, angiogenesis, and migration [3].

The prognosis in NSCLC is poor, with only an $18 \%$ five-year survival rate observed in the general population in the USA [4]. As detection is usually quite late, the tumours are found to be in stages III or IV for 2/3 patients with newly-diagnosed lung malignancy. Standard treatment for this population involves systemic therapy: induction chemotherapy in stage IIIA, chemoradiotherapy (concurrent or sequential) in stage IIIB, or palliative systemic treatment when distant metastases are present. Epidermal growth factor receptor (EGFR) activating mutations are present in 10\% of Caucasians [5], whereas EML4-ALK translocation is present in 2-3\% of the non-Asian NSCLC population $[6,7]$. As most cases of NSCLC do not present a defined target for molecular orientated therapy, platinum-based chemotherapy is the standard approach in the treatment of lung cancer. The objective response rate (ORR), defined as a complete or partial response for cytostatic treatment of advanced disease, ranges from $30 \%$ to $40 \%$.

Lung cancer prognosis is connected with tumour-related (stage, grade) and host-related factors. Established adverse clinical prognostic factors in advanced NSCLC are weight loss and poor performance status, which are also negative predictive factors of response to chemotherapy. Although 
the interaction between the immune system and cancer could play a crucial role in malignancy progression, the relationship remains poorly understood. As the morbidity and mortality rates are so high, it is important to explore the mechanisms that could modify the disease course and sensitivity to systemic treatment.

Because many anti-cancer drugs exert their activity by free radical-mediated mechanisms [8], COPD-associated oxidative stress and inflammation may influence the efficacy of chemotherapy. In addition, in vitro and in vivo studies indicate that cigarette smoking worsens the response of cancer to chemotherapy [9].

The purpose of this study was to investigate the impact of COPD and active smoking on the efficacy of chemotherapy and on complete blood count (CBC) in patients with advanced NSCLC, with regard to systemic inflammatory response and oxidative stress.

\section{Material and methods}

\section{Population}

Retrospective evaluation was carried out using the medical documentation of 50 patients with NSCLC classified as stage III or IV, who began chemotherapy at the Department of Chemotherapy, Medical University of Lodz, in the Copernicus Memorial Hospital of Lodz from 2013 to 2014. The analysis included only patients treated with cisplatin-based chemotherapy doublets, with gemcitabine or vinorelbine as a second drug, and with a present smoking status or a known history of smoking.

COPD was confirmed by spirometry: a positive result was indicated when the ratio of post-bronchodilator forced expiratory volume in one second $\left(F V_{1}\right)$ to forced vital capacity (FVC) was less than 0.7, as given in the Global Initiative for Chronic Obstructive Lung Disease (GOLD) guidelines

Patient characteristics included demographic data (age, sex), tumour response to treatment, complete blood cell count (CBC), and clinicopathological features: subtype of NSCLC, histological grade, performance status, weight loss, FEV 1 value, $\mathrm{FEV}_{1} / \mathrm{FVC}$ ratio, and smoking status and number of pack-years in smokers. Tumour response to treatment was assessed after 2-3 cycles of chemotherapy, based on the rules established by the RECIST 1.1 (Response Evaluation Criteria in Solid Tumours). In two cases, disease progression (PD) was established based only on clinical presentation. The recruitment was approved by the Medi- cal University of Lodz Bioethics Committee (RNN 45/12/KE and 46/12/KE).

\section{Assessment of blood tests}

The initial CBC from peripheral blood was measured before the first treatment cycle. During treatment, CBC was assessed every three weeks (with tolerance from -3 to +8 days) on day one of each cycle before treatment administration. Blood tests were performed by the Synevo laboratory, Copernicus Memorial Hospital, Lodz; spirometry (in 37 prospective cases) was performed using a MasterScreen Body (JAEGER) in the Chair of Experimental and Clinical Physiology, Medical University of Lodz.

\section{Statistical analysis}

All statistical analyses were performed with StatsDirect software (StatsDirect Ltd., Altrincham, UK).

The Friedman test was used to assess the significance of changes in blood parameters during treatment. The comparisons of baseline parameters between different groups were assessed using the $\chi^{2}$ test or Fisher's exact test as appropriate, or the Mann-Whitney test. A $p$-value $<0.05$ was considered statistically significant.

\section{Results}

Among 50 patients enrolled in the analysis, spirometry was assessed in 43 of them. COPD was diagnosed in 21 of those examined (48.8\%), with GOLD stage 1 identified in nine, stage 2 in seven, and stage 3 in three cases. No data about COPD stage was given in two cases. Table 1 summarises the clinical characteristics of the study population according to COPD status.

At the start of chemotherapy, 21 patients (42\%) continued to smoke, 27 (54\%) reported quitting smoking in the past; two patients had never smoked (Table 2).

When data collection was complete, four patients continued chemotherapy - each patient received at least one cycle. Response to treatment was assessed in 45 cases. One patient died due to toxicity before computed tomography examination. In total, a partial response was demonstrated in 18 (40\%) patients, stable disease in 19 (42\%), and cancer progression in eight (18\%).

\section{No-COPD vs. COPD}

Partial remission was observed in seven of the $18 \mathrm{pa}$ tients eligible for response assessment in the COPD group

Table 1. Demographical and clinical characteristics of the study population with COPD and no-COPD subgroups

$\begin{array}{lcccccccccccc} & n & \begin{array}{c}\text { Age } \\ \text { (years) } \\ \text { median }\end{array} & \begin{array}{c}\text { Sex } \\ \text { M/F }\end{array} & \begin{array}{c}\text { Smoking } \\ \text { Y/N/never }\end{array} & \begin{array}{c}\text { DCC } \\ \text { median }\end{array} & \begin{array}{c}\text { Pack- } \\ \text { years } \\ \text { median }\end{array} & \begin{array}{c}\text { Stage } \\ \text { III/IV }\end{array} & \begin{array}{c}\text { Subtype } \\ \text { nonS/S/U }\end{array} & \begin{array}{c}\text { PS } \\ \mathbf{0} / 1 / 2\end{array} & \begin{array}{c}\text { weight loss } \\ >10 \%(Y / N)\end{array} & \begin{array}{c}\text { FEV } \\ \text { (\%) } \\ \text { median }\end{array} & \begin{array}{c}\text { FVC (\%) } \\ \text { median }\end{array} \\ \text { All patients } & 50 & 62 & 30 / 20 & 21 / 27 / 2 & 0 & 38 & 18 / 32 & 20 / 22 / 8 & 13 / 30 / 7 & 14 / 36 & 81.85 & 96.5 \\ \text { COPD } & 21 & 62 & 12 / 9 & 9 / 12 / 0 & 0 & 40 & 6 / 15 & 8 / 9 / 4 & 5 / 11 / 5 & 6 / 15 & 68.9 & 98.15 \\ \text { No-COPD } & 22 & 62 & 12 / 10 & 9 / 11 / 2 & 0 & 30 & 11 / 11 & 8 / 10 / 4 & 6 / 14 / 2 & 6 / 16 & 88.8 \\ \text { p value } & & 0.8 & 0.86 & 0.6 & 0.97 & 0.37 & 0.15 & >0.99 & 0.49 & 0.92 & 0.03 & 0.67\end{array}$

COPD - chronic obstructive pulmonary disease; $n$ - number of participants; $M$ - male, $F$ - female, DCC - daily cigarette consumption, $Y$-yes; $N$ - no; nonS - nonsquamous carcinoma (adenocarcinoma or large-cell carcinoma); $S$ - squamous carcinoma; $U$ - unable to assess, $P S$ - ECOG performance status 
Table 2. Demographical and clinical characteristics of the study: smokers and ex-smokers subgroups

$\begin{array}{lccccccccc} & n & \begin{array}{c}\text { Age (years) } \\ \text { median }\end{array} & \begin{array}{c}\text { Sex } \\ \text { M/F }\end{array} & \begin{array}{c}\text { DCC } \\ \text { median }\end{array} & \begin{array}{c}\text { Pack-years } \\ \text { median }\end{array} & \begin{array}{c}\text { Stage } \\ \text { III/IV }\end{array} & \begin{array}{c}\text { Subtype } \\ \text { nonS } / \mathrm{S} / \mathrm{U}\end{array} & \begin{array}{c}\text { PS } \\ 0 / 1 / 2\end{array} & \begin{array}{c}\text { Weight loss } \\ >10 \%(\mathrm{Y} / \mathrm{N})\end{array} \\ \text { Smokers } & 21 & 62 & 15 / 6 & 10 & 40 & 6 / 15 & 7 / 10 / 4 & 4 / 14 / 3 & 12 / 9 \\ \text { Ex-smokers } & 29 & 62 & 15 / 14 & 0 & 30 & 11 / 18 & 13 / 12 / 4 & 9 / 16 / 4 & 2 / 27 \\ p \text { value } & & 0.54 & 0.16 & <0.0001 & 0.09 & 0.49 & 0.74 & 0.66 & <0.0001\end{array}$

COPD - chronic obstructive pulmonary disease; $n$ - number of participants; DCC - daily cigarette consumption; $M$ - male; $F$ - female; nonS - non-squamous carcinoma (adenocarcinoma or large-cell carcinoma); $S$-squamous carcinoma; $U$ - unable to assess; PS - ECOG performance status

Table 3. Differences of analysed parameters (median value and change after treatment) depending on variables and time point during chemotherapy

\begin{tabular}{|c|c|c|c|c|c|c|c|}
\hline & Entire population & No-COPD & COPD & $\begin{array}{l}\text { No-COPD vs. } \\
\text { COPD }\end{array}$ & Smokers & Ex-smokers & $\begin{array}{l}\text { Smokers vs. } \\
\text { ex-smokers }\end{array}$ \\
\hline WBC $\left(\times 10^{9} / 1\right)$ & 9.27 & 9.65 & 8.83 & NS & 9.94 & 8.7 & $p=0.01$ \\
\hline post 1c. vs. 0 & $\downarrow(p<0.0001)$ & $\downarrow(p=0.0002)$ & $\downarrow(p=0.001)$ & & $\downarrow(p=0.002)$ & $\downarrow(p<0.0001)$ & \\
\hline post 3c. vs. 0 & $\downarrow(p<0.0001)$ & $\downarrow(p=0.0001)$ & $\downarrow(p=0.001)$ & & $\downarrow(p=0.001)$ & $\downarrow(p<0.0001)$ & \\
\hline neutrophils $\left(\times 10^{9} / 1\right)$ & 5.84 & 6.275 & 5.66 & NS & 6.47 & 5.61 & $p=0.037$ \\
\hline post 1c. vs. 0 & $\downarrow(p<0.0001)$ & $\downarrow(p<0.0001)$ & $\downarrow(p<0.0001)$ & & $\downarrow(p<0.0001)$ & $\downarrow(p<0.0001)$ & \\
\hline post 3c. vs. 0 & $\downarrow(p<0.0001)$ & $\downarrow(p<0.0001)$ & $\downarrow(p<0.0001)$ & & $\downarrow(p<0.0001)$ & $\downarrow(p<0.0001)$ & \\
\hline lymphocytes $\left(\times 10^{9} /\right.$ l) & 2.05 & 2.31 & 1.81 & $p=0.0374$ & 2.05 & 2.03 & NS \\
\hline post 1c. vs. 0 & NS & $\uparrow N S\left(p=0.053^{\star}\right)$ & NS & & NS & $\uparrow \mathrm{NS}(p=0.08)$ & \\
\hline post 3c. vs 0 & NS & NS & NS & & NS & NS & \\
\hline monocytes $\left(\times 10^{9} / 1\right)$ & 0.86 & 0.9 & 0.85 & NS & 0.88 & 0.85 & NS \\
\hline post 1c. vs. 0 & $\uparrow(p=0.005)$ & $\uparrow\left(p=0.004^{\star}\right)$ & NS & & $\uparrow N S\left(p=0.059^{*}\right)$ & $\uparrow\left(p=0.004^{\star}\right)$ & \\
\hline post 3c. vs. 0 & $\uparrow(p=0.01)$ & $\uparrow\left(p=0.004^{\star}\right)$ & NS & & $\uparrow N S\left(p=0.059^{\star}\right)$ & $\uparrow N S\left(p=0.087^{\star}\right)$ & \\
\hline eosynocytes $\left(\times 10^{9} / 1\right)$ & 0.16 & 0.195 & 0.14 & NS & 0.2 & 0.16 & NS \\
\hline post 1c. vs. 0 & $\downarrow(p=0.0001)$ & $\downarrow(p=0.002)$ & $\downarrow(p=0.008)$ & & $\downarrow(p=0.002)$ & $\downarrow(p=0.003)$ & \\
\hline post 3c. vs. 0 & $\downarrow(p<0.0001)$ & $\downarrow(p=0.001)$ & $\downarrow(p=0.025)$ & & $\downarrow(p=0.001)$ & $\downarrow(p=0.001)$ & \\
\hline basocytes $\left(\times 10^{9} / \mathrm{l}\right)$ & 0.04 & 0.045 & 0.04 & NS & 0.05 & 0.04 & NS \\
\hline post 1c. vs. 0 & NS & NS & NS & & NS & NS & \\
\hline post 3c. vs. 0 & $\downarrow\left(p=0.046^{* *}\right)$ & NS & NS & & NS & NS & \\
\hline haemoglobin (g/dl) & 13.2 & 13.65 & 12.8 & NS & 12.8 & 13.9 & NS \\
\hline post 1c. vs. 0 & $\downarrow(p<0.0001)$ & $\downarrow(p<0.0001)$ & $\downarrow(p=0.008)$ & & $\downarrow(p=0.0002)$ & $\downarrow(p<0.0001)$ & \\
\hline post 3c. vs. 0 & $\downarrow(p<0.0001)$ & $\downarrow(p<0.0001)$ & $\downarrow(p<0.0001)$ & & $\downarrow(p<0.0001)$ & $\downarrow(p<0.0001)$ & \\
\hline $\operatorname{PLT}\left(\times 10^{9} / \mathrm{l}\right)$ & 304 & 304 & 298 & NS & 316 & 266 & $p=0.049$ \\
\hline post 1c. vs. 0 & $\uparrow(p<0.0001)$ & $\uparrow(p<0.0001)$ & $\uparrow\left(p=0.027^{\star}\right)$ & & $\uparrow(p=0.001)$ & $\uparrow(p<0.0001)$ & \\
\hline post 3c. vs. 0 & NS & NS & NS & & NS & $\uparrow(p=0.046)$ & \\
\hline NLR & 28.5 & 2.71 & 2.97 & NS & 3.3 & 2.8 & NS \\
\hline post 1c. vs. 0 & $\downarrow(p<0.0001)$ & $\downarrow(p<0.0001)$ & $\downarrow(p<0.0001)$ & & $\downarrow(p<0.0001)$ & $\downarrow(p<0.0001)$ & \\
\hline post 3c. vs. 0 & $\downarrow(p<0.0001)$ & $\downarrow(p<0.0001)$ & $\downarrow(p<0.0001)$ & & $\downarrow(p<0.0001)$ & $\downarrow(p<0.0001)$ & \\
\hline LMR & 2.47 & 2.54 & 2.28 & NS & 2.20 & 2.57 & NS \\
\hline post 1c. vs. 0 & $\downarrow(p=0.018)$ & NS & NS & & $\downarrow(p=0.045)$ & NS & \\
\hline post 3c. vs. 0 & $\downarrow(p=0.0001)$ & $\downarrow\left(p=0.016^{\star}\right)$ & $\downarrow(p=0.005)$ & & $\downarrow(p=0.019)$ & $\downarrow(p=0.003)$ & \\
\hline PLR & 146.91 & 136.19 & 162.38 & NS & 161.63 & 137.02 & NS \\
\hline post 1c. vs. 0 & $\uparrow(p<0.0001)$ & $\uparrow(p=0.002)$ & $\uparrow\left(p=0.016^{\star}\right)$ & & $\uparrow(p=0.016)$ & $\uparrow(p<0.0001)$ & \\
\hline post 3c. vs. 0 & NS & NS & NS & & NS & NS & \\
\hline
\end{tabular}

* without significant change of values in general Friedman test: only one value tends to be different to another ( $p: 0.05-0.1)$

${ }^{* *}$ without significant change of values in general Friedman test: only one value tends to be different to another $(p \geq 0.1)$

0 - baseline; 1c. - first cycle of chemotherapy; 3c. - third cycle of chemotherapy; WBC - white blood cells; PLT - platelets; UA - uric acid; LDH - lactate dehydrogenase; NLR - neutrophil-to-lymphocyte ratio; $L M R$ - lymphocyte-to-monocyte ratio; PLR - platelet-to-lymphocyte ratio; NS - non-significant;

$\uparrow$-increase; $\downarrow$-decrease. COPD - chronic obstructive pulmonary disease; NS - not statistically significant 
compared to 10 of the 20 patients without COPD. Stable disease occurred in 8/18 COPD patients and 7/20 nonCOPD patients. Disease progression was observed in 3/18 COPD and 3/20 non-COPD patients. The differences were non-significant $(p=0.91)$.

The non-COPD population demonstrated a higher pretreatment absolute lymphocyte count (ALC) than the COPD population ( $\left.2.31 \mathrm{vs.} 1.81 \times 10^{9} / \mathrm{l} ; p=0.0374\right)$. An insignificant tendency for increased ALC was found in the nonCOPD patients after the first cycle of chemotherapy ( $p=$ 0.053) but not in the COPD group. Similarly, the non-COPD group also demonstrated elevated absolute monocyte count (AMC) after the start of the treatment and after the third cycle (both $p=0.004$ ). Both populations demonstrated NLR reduction after the fist and third cycles, LMR reduction after the thirrd cycle, and PLR enlargement after the first cycle. A detailed comparison is presented in Table 3.

\section{Smokers vs. ex-smokers}

Of the patients eligible for response assessment, partial remission was documented in 7 of the 19 members of the

Table 4. Differences of analysed parameters (median value and change after treatment) depending on tumour response and time point during chemotherapy

\begin{tabular}{|c|c|c|c|c|c|}
\hline & PR & SD & PD & PR vs. SD & PR vs. PD \\
\hline WBC $\left(\times 10^{9} / l\right)$ & 9.58 & 9.24 & 7.56 & NS & NS $(p=0.078)$ \\
\hline post 1c. vs. 0 & $\downarrow(p<0.0001)$ & $\downarrow(p=0.001)$ & NS & & \\
\hline post 3c. vs. 0 & $\downarrow(p<0.0001)$ & $\downarrow(p=0.002)$ & NS & & \\
\hline neutrophils $\left(\times 10^{9} / 1\right)$ & 6.39 & 5.61 & 4.67 & NS & NS $(p=0.064)$ \\
\hline post 1c. vs. 0 & $\downarrow(p<0.0001)$ & $\downarrow(p<0.0001)$ & NS & & \\
\hline post 3c. vs. 0 & $\downarrow(p<0.0001)$ & $\downarrow(p<0.0001)$ & $\downarrow\left(p=0.032^{\star}\right)$ & & \\
\hline lymphocytes (× 10\%/l) & 2.04 & 2.27 & 2.16 & NS & NS \\
\hline post 1c. vs. 0 & NS & NS & NS & & \\
\hline post 3c. vs. 0 & NS & NS & $\uparrow(p=0.003)$ & & \\
\hline monocytes $\left(\times 10^{9} / \mathrm{l}\right)$ & 0.97 & 0.87 & 0.65 & NS & $p=0.021$ \\
\hline post 1c. vs. 0 & NS & $\uparrow(p=0.002)$ & NS & & \\
\hline post 3c. vs. 0 & NS & $\uparrow(p<0.0001)$ & NS & & \\
\hline eosynocytes (× 109/l) & 0.16 & 0.15 & 0.2 & NS & NS \\
\hline post 1c. vs. 0 & $\downarrow(p=0.01)$ & $\downarrow(p=0.008)$ & $\downarrow\left(p=0.032^{\star}\right)$ & & \\
\hline post 3c. vs. 0 & $\downarrow(p=0.0005)$ & $\downarrow(p=0.003)$ & NS & & \\
\hline basocytes $\left(\times 10^{9} / 1\right)$ & 0.05 & 0.04 & 0.05 & NS & NS \\
\hline post 1c. vs. 0 & NS & NS & $\downarrow N S\left(p=0.07^{\star \star}\right)$ & & \\
\hline post 3c. vs. 0 & $\downarrow\left(p=0.023^{\star}\right)$ & NS & NS & & \\
\hline haemoglobin (g/dl) & 13.15 & 13.9 & 13.1 & NS & NS \\
\hline post 1c. vs. 0 & $\downarrow(p=0.001)$ & $\downarrow(p<0.0001)$ & $\downarrow(p=0.012)$ & & \\
\hline post 3c. vs. 0 & $\downarrow(p<0.0001)$ & $\downarrow(p<0.0001)$ & $\downarrow(p<0.003)$ & & \\
\hline PLT $\left(\times 10^{9} / \mathrm{l}\right)$ & 279.5 & 298 & 325.5 & NS & NS \\
\hline post 1c. vs. 0 & $\uparrow(p=0.001)$ & $\uparrow(p<0.0001)$ & NS & & \\
\hline post 3c. vs. 0 & NS & NS & NS & & \\
\hline NLR & 2.88 & 3.12 & 2.28 & NS & NS \\
\hline post 1c. vs. 0 & $\downarrow(p<0.0001)$ & $\downarrow(p<0.0001)$ & NS & & \\
\hline post 3c. vs. 0 & $\downarrow(p<0.0001)$ & $\downarrow(p<0.0001)$ & $\downarrow(p=0.003)$ & & \\
\hline LMR & 1.94 & 2.69 & 3.09 & NS & NS \\
\hline post 1c. vs. 0 & NS & $\downarrow(p<0.0001)$ & NS & & \\
\hline post 3c. vs. 0 & NS & $\downarrow(p<0.0001)$ & NS & & \\
\hline PLR & 150.23 & 147.52 & 153.96 & NS & NS \\
\hline post 1c. vs. 0 & $\uparrow(p=0.001)$ & $\uparrow(p<0.0001)$ & NS & & \\
\hline post 3c. vs. 0 & $\uparrow(p=0.024)$ & NS & $\downarrow(p=0.003)$ & & \\
\hline
\end{tabular}


current smoker population, and in 11 of the 26 ex-smokers. Stable disease was observed in $8 / 19$ smokers and $11 / 26$ ex-smokers. Disease progression was seen in $4 / 19$ of smokers and $4 / 26$ of ex-smokers. The differences were non-significant $(p=0.92)$.

Pretreatment scores for WBC, absolute neutrophil count (ANC), and platelet number (PLT) were higher in the smoker than in the ex-smoker population: WBC $9.94 \mathrm{vs.} 8.7\left(\times 10^{9} / 1\right)$; $p=0.01$; ANC 6.47 vs. $5.61\left(\times 10^{9} / l\right) ; p=0.037$; PLT 316 vs. $266\left(\times 10^{9} / l\right) ; p=0.049$. Increases in PLT level following the third cycle were observed in the ex-smokers but no change was observed in the smokers. A non-significant trend ( $p=0.08)$ towards early ALC increase was noted only in the ex-smokers. Early LMR decrease was demonstrated only in active smokers. The results are presented in Table 3. Differences in laboratory parameters between the
groups depending on response to treatment

Baseline AMC was significantly higher in the PR group than in the PD group: 0.97 vs. $0.65\left(\times 10^{9} / l\right)(p=0.021)$ A non-significant trend towards higher WBC and ANC was observed in the PR group: 9.58 vs. $7.56\left(\times 10^{9} / l\right)$ for WBC $(p=0.078) ; 6.39$ vs. $4.67\left(\times 10^{9} / l\right)$ for ANC $(p=0.064)$. No other differences were observed in baseline parameters (Table 4). Contrary to patients with PR or SD, the PD group demonstrated no significant decrease in WBC after cycles 1 and 3, no decrease in ANC or NLR (after 1 cycle), and no early increase of PLT or PLR during chemotherapy. On the other hand, a noticeable decrease of PLR was observed after three cycles as a result of elevated ALC in the poor response group. AMC elevation and consequent LMR reduction was reported only in the SD group, while greater PLR was observed in three cycles of treatment only in the PR group.

\section{Discussion}

Chronic obstructive pulmonary disease (COPD) is observed in about $50 \%$ of patients diagnosed with lung cancer $[10,11]$. Airflow limitation is an indicator of greater risk of respiratory complications and cardiac arrhythmias that may potentially affect the process of diagnosis and treatment of lung cancer $[12,13]$. An analysis of studies based on NSCLC patients following surgery revealed an association between the coexistence of both diseases and poorer prognosis [11, 14]. However, a prospective trial of 324 patients diagnosed with advanced NSCLC treated with systemic therapy revealed no significant differences in survival between the COPD and non-COPD groups [10]. Thus, the coexistence of COPD may adversely affect prognosis only in patients with early NSCLC, who are candidates for radical surgery. Our results are concordant with these observations.

Cigarette smoking generates about 6000 toxic compounds, carcinogens, radical solids, and oxidants [15]. Tobacco components affect the respiratory system by the generation of oxidative stress and promotion of inflammation. Consequently, these mechanisms induce epithelial cell damage or cell death with simultaneous activation of reactive damage repair and enhanced proliferation [16]. The dichotomous influence of smoking is a cause of COPD (cell death) and lung cancer proliferation. Cigarette smoking has also been found to have a negative impact on the response to anti-cancer therapy, both in vitro and in vivo [9]. However, no differences have been found in response to chemotherapy depending on current smoking status.

COPD is accompanied by chronic inflammation in the airways. This inflammation has a specific pattern with increased numbers of cytotoxic $T$ lymphocytes and coexisting infiltration by neutrophils and macrophages that release inflammatory mediators and oxidants [17]. The conception of the protective role played by the immune system against cancer has already been documented [18]; however, the proposition by Virchow (1863) that cancer development and progression are connected with inflammation has yet to be disproved $[3,19]$.

A convincing body of evidence suggests that macrophages located in the tumour microenvironment (tumour-associated macrophages - TAM) can kill tumour cells or foster cancer promotion by the modulation of cytotoxic T-cell activity [20]. The presence of a higher number of monocytes, circulating blood precursors of macrophages, corresponds with poor prognosis and worse response to treatment in many malignancies [21-23]. Lin et al. note that $A M C \geq 0.45 \times 10^{9} / 1$ is a significant adverse prognostic factor in metastatic NSCLC (OS HR = 2.04) [24]. Our findings indicate no difference in AMC between the COPD and non-COPD groups, or between current smokers and ex-smokers. However, higher baseline AMC was found in patients with better response to chemotherapy than those with progression of cancer $(p=0.021)$.

The presence of a lower lymphocyte-to-monocyte ratio (LMR) was an adverse prognostic biomarker for resected NSCLC (OS HR = 1.51; DFS HR = 1.34) [25] and for other malignancies [26, 27]. In metastatic NSCLC, LMR $\geq 4.56$ was found to correlate with better PFS $(H R=0.66)$ and OS $(H R$ $=0.53$ ) [24]. In our analysis, no differences in pretreatment LMR values were observed between groups, and LMR did not predict response to therapy.

Lymphocytes play a crucial role in the cell-mediated host immune response to tumours. Infiltration of tumours by lymphocytes (tumour-infiltrating lymphocytes - TILS) correlates with better prognosis in triple-negative breast cancer [28] or ovarian cancer [29]. Several trials investigating whether peripheral lymphocyte level can be used as a marker to predict the course of cancer found that higher levels are associated with a positive effect on outcome [30], and lower lymphocyte counts with a poor outcome [21]. Such results were obtained both in early-stage and advanced NSCLC [31, 32]. Higher baseline ALC was found in the absence of COPD, but no baseline difference was found between groups depending on response to treatment. Nevertheless, disease progression was associated with an increase of ALC during treatment.

Pretreatment absolute neutrophil count (ANC) is known to be an independent indicator of poor prognosis in lung cancer patients [31]. An analysis by Teramukai et al. found that in patients diagnosed with stage IIIB or IV NCSLC treated with chemotherapy, with a cut-off value of $4.5 \times 10^{9}$ neutrophils/l measured before treatment, low-neutrophil count was significantly associated with longer survival (median 
OS 19.3 for the low-neutrophil group vs. 10.2 months for the high-neutrophil group) [33]. Higher pretreatment ANC was found in current smokers than ex-smokers. Patients who had better response to chemotherapy tended to have higher baseline ANC than those who had progression ( $p=0.06$ ); however, a significant decline in ANC was observed only in those with disease control.

Many trials have evaluated the prognostic impact of NLR (defined as absolute neutrophil count divided by absolute lymphocyte count) as a surrogate marker of systemic inflammatory response in malignancy. Based on these results it has been proposed that NLR be assessed as an independent prognostic factor for survival, regardless of cancer localisation [34-36]. In non-small cell lung cancer patients treated with EGFR-TKIs (tyrosine kinase inhibitors), elevated NLR ( $\geq 3.5$ ) was associated with lower objective response rate (52\% vs. 79\%), and shorter PFS (median 8.2 vs. 10.6 months; HR = 3.90) and OS (17.2 vs. 23.2 months; $H R=3.29$ ) [37]. Among patients enrolled in the First-SIGNAL prospective study (non-smokers with adenocarcinoma treated with chemotherapy or EGFR-TKI), NLR was assessed at two points in time: at baseline and after one cycle of treatment. The study showed that significant reduction of NLR during treatment was associated with better tumour response (in the chemotherapy arm, median percentage changes of NLR in PR, SD, and PD subgroups were $50 \%, 41 \%$, and $20 \%$, respectively) and longer survival time (median OS 20.7 vs. 7.9 months) [38]. Another trial conducted in a typical population of patients with advanced NSCLC, with an NLR cut-off point of 2.63, documented that lower pretreatment NLR and its decline during chemotherapy correlated significantly with better response to chemotherapy [39]. Our analysis confirms the association between early NLR reduction and disease control: the change was observed in patients with PR and SD after the first cycle of chemotherapy, although a significant decrease was also observed after the third cycle in the PD population.

In a meta-analysis of trials, pretreatment platelet-to-lymphocyte ratio (PLR) was found to be an adverse prognostic factor in gastric cancer, colorectal cancer, ovarian cancer, and NSCLC [40]. In a prospective study of 210 patients with advanced NSCLC, the cut-off value for NRL at pretreatment was defined as 152.6. The study showed that elevated NLR was associated with poor response to first-line chemotherapy $(\mathrm{OR}=4.50)$ and worse $\mathrm{OS}(\mathrm{HR}=2.03)$ [41]. Despite no differences in baseline PLR, our study showed early increase of PLR in the PR and SD groups. After the third cycle, PLR was higher than baseline in the PR group but lower in the PD population. COPD or smoking status did not affect PLR.

A major limitation of our study is that it is a retrospective study involving a relatively small number of patients. In addition, as the analysed variables could be influenced by other factors, it is important to validate the proposed predictive and prognostic factors and their correlation with COPD or smoking status in future prospective studies.

In conclusion, COPD and smoking induce chronic systemic inflammation and oxidative stress, which influence standard laboratory tests. Our findings indicate that these processes did not change the response rate of lung can- cer to chemotherapy. A literature review reveals that some CBC parameters may act as potentially useful biomarkers of tumour response to chemotherapy and patient survival. However, as this is a retrospective study with a limited population size, further prospective studies are warranted.

The authors declare no conflict of interest.

\section{References}

1. Ferlay J, Soerjomataram I, Dikshit R, et al. Cancer incidence and mortality worldwide: Sources, methods and major patterns in GLOBOCAN 2012. Int J Cancer 2015; 136: E359-86.

2. Stämpfli MR, Anderson GP. How cigarette smoke skews immune responses to promote infection, lung disease and cancer. Nat Rev Immunol 2009; 9: 377-84.

3. Coussens LM, Werb Z. Inflammation and cancer. Nature 2002; 420: 860-7.

4. Siegel R, Ma J, Zou Z, Jemal A. Cancer statistics, 2014. CA Cancer J Clin 2014; 64: 9-29.

5. Szumera-Ciećkiewicz A, Olszewski WT, Tysarowski A, et al. EGFR mutation testing on cytological and histological samples in nonsmall cell lung cancer: a Polish, single institution study and systematic review of European incidence. Int J Clin Exp Pathol 2013; 6: 2800-12.

6. Bergethon K, Shaw AT, Ignatius Ou SH, et al. ROS1 Rearrangements Define a Unique Molecular Class of Lung Cancers. J Clin Oncol 2012; 30: 863-70.

7. Perner S, Wagner PL, Demichelis F, et al. EML4-ALK fusion lung cancer: a rare acquired event. Neoplasia 2008; 10: 298-302.

8. Look MP, Musch E. Lipid peroxides in the polychemotherapy of cancer patients. Chemotherapy 1994; 40: 8-15.

9. Warren GW, Romano MA, Kudrimoti MR, et al. Nicotinic modulation of therapeutic response in vitro and in vivo. Int J Cancer 2012; 131: 2519-27.

10. Izquierdo JL, Resano P, El Hachem A, Graziani D, Almonacid C, Sánchez IM. Impact of COPD in patients with lung cancer and advanced disease treated with chemotherapy and/or tyrosine kinase inhibitors. Int J Chron Obstruct Pulmon Dis 2014; 9: 1053-8.

11. López-Encuentra A, Astudillo J, Cerezal J, et al. Prognostic value of chronic obstructive pulmonary disease in 2994 cases of lung cancer. Eur J Cardiothorac Surg 2005; 27: 8-13.

12. Sekine Y, Kesler KA, Behnia M, Brooks-Brunn J, Sekine E, Brown JW. COPD may increase the incidence of refractory supraventricular arrhythmias following pulmonary resection for non-small cell lung cancer. Chest 2001; 120: 1783-90.

13. Algar FJ, Alvarez A, Salvatierra A, Baamonde C, Aranda JL, López-Pujol FJ. Predicting pulmonary complications after pneumonectomy for lung cancer. Eur J Cardiothorac Surg 2003; 23: 201-8.

14. Zhai R, Yu X, Shafer A, Wain JC, Christiani DC. The impact of COexisting COPD on survival of patients with early-stage non-small cell lung cancer undergoing surgical resection. Chest 2014; 145: 346-53.

15. Church DF, Pryor WA. Free-radical chemistry of cigarette smoke and its toxicological implications. Environ Health Perspect 1985; 64: 111-26.

16. Ryoo HD, Bergmann A. The role of apoptosis-induced proliferation for regeneration and cancer. Cold Spring Harb Perspect Biol 2012; 4: a008797.

17. M. Global initiative for Chronic Obstructive Lung Disease (GOLD). Global Strategy for Diagnosis, and Prevention of COPD. Update 2014. Available at: http://www.goldcopd.com/uploads/, users/ files/GOLD_Report_2014_Oct30.pdf. Dostęp w dn. 08/01/2015

18. Dunn GP, Bruce AT, Ikedā H, Old LJ, Schreiber RD. Cancer immunoediting: from immunosurveillance to tumor escape. Nat Immunol 2002; 3: 991-8.

19. Balkwill F, Mantovani A. Inflammation and cancer: back to Virchow? Lancet 2001; 357: 539-45. 
20. Qian BZ, Pollard JW. Macrophage diversity enhances tumor progression and metastasis. Cell 2010; 141: 39-51.

21. Bishara S, Griffin M, Cargill A, et al. Pre-treatment white blood cell subtypes as prognostic indicators in ovarian cancer. Eur J Obstet Gynecol Reprod Biol 2008; 138: 71-5.

22. Tsai YD, Wang CP, Chen CY, et al. Pretreatment circulating monocyte count associated with poor prognosis in patients with oral cavity cancer. Head Neck 2014; 36: 947-53.

23. Botta C, Barbieri V, Ciliberto D, et al. Systemic inflammatory status at baseline predicts bevacizumab benefit in advanced non-small cell lung cancer patients. Cancer Biol Ther 2013; 14: 469-75.

24. Lin GN, Peng JW, Xiao JJ, Liu DY, Xia ZJ. Prognostic impact of circu lating monocytes and lymphocyte-to-monocyte ratio on previously untreated metastatic non-small cell lung cancer patients receiving platinum-based doublet. Med Oncol 2014; 31: 70.

25. Hu P,Shen H, Wang G, Zhang P, Liu Q, Du J. Prognostic significance of systemic inflammation-based lymphocyte-monocyte ratio in patients with lung cancer: based on a large cohort study. PLoS One 2014; 9: e108062.

26. Li YL, Pan YY, Jiao Y, Ning J, Fan YG, Zhai ZM. Peripheral blood lymphocyte/monocyte ratio predicts outcome for patients with diffuse large B cell lymphoma after standard first-line regimens. Ann Hematol 2014; 93: 617-26.

27. Li J, Jiang R, Liu WS, et al. A large cohort study reveals the association of elevated peripheral blood lymphocyte-to-monocyte ratio with favorable prognosis in nasopharyngeal carcinoma. PLoS One 2013; 8: e83069.

28. Adams S, Gray RJ, Demaria S, et al. Prognostic value of tumor-infiltrating lymphocytes in triple-negative breast cancers from two phase III randomized adjuvant breast cancer trials: ECOG 2197 and ECOG 1199. J Clin Oncol 2014; 32: 2959-67.

29. Zhang L, Conejo-Garcia JR, Katsaros D, et al. Intratumoral T cells, recurrence, and survival in epithelial ovarian cancer. N Engl J Med 2003; 348: 203-13.

30. Dou X, Wang RB, Yan HJ, et al. Circulating lymphocytes as predic tors of sensitivity to preoperative chemoradiotherapy in rectal cancer cases. Asian Pac J Cancer Prev 2013; 14: 3881-5.

31. Hespanhol V, Queiroga H, Magalhăes A, Santos AR, Coelho M, Marques A. Survival predictors in advanced non-small cell lung cancer. Lung Cancer 1995; 13: 253-67.

32. Zhang J, Huang SH, Li H, et al. Preoperative lymphocyte count is a favorable prognostic factor of disease-free survival in non-smallcell lung cancer. Med Oncol 2013; 30: 352

33. Teramukai S, Kitano T, Kishida Y, et al. Pretreatment neutrophi count as an independent prognostic factor in advanced nonsmall-cell lung cancer: an analysis of Japan Multinational Trial Organisation LCO0-03. Eur J Cancer 2009; 45: 1950-8.

34. Azab B, Bhatt VR, Phookan J, et al. Usefulness of the neutrophil-to-lymphocyte ratio in predicting short- and long-term mortality in breast cancer patients. Ann Surg Oncol 2012; 19: 217-24.

35. Yamanaka T, Matsumoto S, Teramukai S, Ishiwata R, Nagai $Y$, Fukushima $M$. The baseline ratio of neutrophils to lymphocytes is associated with patient prognosis in advanced gastric cancer. Oncology 2007; 73: 215-20.

36. Kao SC, Pavlakis N, Harvie R, et al. High blood neutrophil-to-lym phocyte ratio is an indicator of poor prognosis in malignant me sothelioma patients undergoing systemic therapy. Clin Cancer Res 2010; 16: 5805-13

37. Lin GN, Peng JW, Liu PP, Liu DY, Xiao JJ, Chen XQ. Elevated neutro phil-to-lymphocyte ratio predicts poor outcome in patients with advanced non-small-cell lung cancer receiving first-line gefitinib or erlotinib treatment. Asia Pac J Clin Oncol 2014; doi: 10.1111/ ajco.12273.

38. Lee Y, Kim SH, Han JY, Kim HT, Yun T, Lee JS. Early neutrophil-to-lymphocyte ratio reduction as a surrogate marker of prognosis in nev er smokers with advanced lung adenocarcinoma receiving gefi tinib or standard chemotherapy as first-line therapy. J Cancer Res Clin Oncol 2012; 138: 2009-16.

39. Yao Y, Yuan D, Liu H, Gu X, Song Y. Pretreatment neutrophil to lym phocyte ratio is associated with response to therapy and progno sis of advanced non-small cell lung cancer patients treated with first-line platinum-based chemotherapy. Cancer Immunol Immunother 2013; 62: 471-9.

40. Zhou X, Du Y, Huang Z, et al. Prognostic value of PLR in various cancers: a meta-analysis. PLoS One 2014; 9: e101119.

41. Liu H, Wu Y, Wang Z, et al. Pretreatment platelet-to-lymphocyte ratio $(P L R)$ as a predictor of response to first-line platinum-based chemotherapy and prognosis for patients with non-small cell lung cancer. J Thorac Dis 2013; 5: 783-9.

\section{Address for correspondence}

\section{Rafał Czyżykowski}

Chemotherapy Department

Mikołaja Kopernika Memorial Hospital in Lodz

Medical University of Lodz

Pabianicka 62

93-513 Lodz, Poland

e-mail: rafal.czyzykowski@wp.pl

Submitted: 30.04 .2015

Accepted: 22.06.2016 